\title{
Establishing a Dynamic Elastic Modulus Prediction Model of Larch Based on Nondestructive Testing Data
}

\author{
Liting Cheng, ${ }^{a}$ Wei Wang ${ }^{b, c, d, *}$ Zhiguo Yang, ${ }^{e}$ and Jian Dai, ${ }^{b, c, d, *}$
}

To accurately evaluate the dynamic elastic modulus $\left(E_{d}\right)$ of wood in ancient timberwork buildings, the new materials of larch were used as the research object, and the stress wave nondestructive testing method was used to determine it. Based on nondestructive testing data, this paper proposed a method for predicting the $E_{d}$ of larch using the principle of information diffusion. It selected the distance (D) from the bark to the pith in the cross-section of the wood and the height $(\mathrm{H})$ from the base to the top in the radial section of the wood. The fuzzy diffusion relationships between the two evaluation indexes and the $E_{\mathrm{d}}$ were established using the information diffusion principle and the first- and second-order fuzzy approximate inferences in the fuzzy information optimization process. The calculation results showed that the dynamic elastic modulus model constructed by the information diffusion method can better predict the $E_{d}$ of larch. The coefficient of determination between the measured value and the predicted value of the Ed was 0.861, they were in good agreement. The weights of the two influencing factors were 0.7 and 0.3 , respectively, the average relative error of the fitted sample data was the minimum, which was $8.55 \%$. This prediction model provided a strong basis for field inspection.

Keywords: Stress wave; Distance base-top; Fuzzy matrix; Information diffusion

Contact information: a: College of Architecture and Civil Engineering, Beijing University of Technology, Beijing 100124, China; b: College of Architecture and Urban Planning, Beijing University of Technology, Beijing 100124, China; c: Beijing Engineering Technology Research Center for Historic Building Protection, Beijing University of Technology, Beijing 100124, China; d: Key Science Research Base of Safety Assessment and Disaster Mitigation for Traditional Timber Structure (Beijing University of Technology), State Administration for Cultural Heritage, Beijing 100124,China; e: College of Petroleum Engineering, China University of Petroleum (Beijing), Beijing 102249, China;

*Corresponding author: chenglting@126.com;ieeww@bjut.edu.cn

\section{INTRODUCTION}

Wood is an important renewable natural resource and is widely used in construction, furniture, and bridges (Hou 2019). Because wood occupies an important position in ancient timberwork buildings, it has become one of the important goals of wood research to effectively, quickly, and accurately test the timber property of the wooden structure on site without damaging the material itself and the original structure of the ancient wooden structure members ( $\mathrm{Li} 2015$ ). Among the wood property indexes, elastic modulus is an important wood property index that can reflect the wood's ability to change under load (Tian et al. 2017; Cavalheiro et al. 2018). At the same time, it is an important basis for nondestructive testing of wood and automatic classification of wood strength (Wang and Zhang 2006). Therefore, accurately predicting the elastic modulus of wood has an important practical significance. The traditional elastic modulus detection method is through mechanical experiments, which are destructive and not suitable for ancient 
buildings. In recent years, nondestructive testing technologies have been widely used in the field of wood property testing (Biechele et al. 2011; Ming et al. 2013; Chang 2017). The nondestructive testing methods currently applied to the determination of the elastic modulus of wooden components of ancient buildings are: ultrasonic method (Moreno-Chan et al. 2011), stress wave technology (Guan et al. 2013; Menezzi et al. 2014), SilviScan (Xu et al. 2012; Dahlen et al. 2018), and micro-drilling resistance instrument technology (Zhu et al. 2011; Sun 2012; Sun et al. 2012). These techniques have been widely used in nondestructive testing of wood properties (Zhu 2012; Dackermann et al. 2016; Wang et al. 2016; Haseli et al. 2020). It is of great practical significance to predict the elastic modulus index of the whole wood by using a reasonable calculation model, based on nondestructive testing technology to detect the $E_{\mathrm{d}}$ of wood.

Information diffusion (Huang 2005; Hao et al. 2010) is a fuzzy mathematical processing method for set-valued samples that considers the optimal use of sample fuzzy information to make up for insufficient information. It turns a sample point of distinct values into a fuzzy set (Wang et al. 2019). It is built and developed on the basis of information distribution methods, the basic idea is to directly transfer the original information to the fuzzy relationship in a certain way, thereby avoiding the calculation of the membership function, so as to retain the original information carried by the original data to the greatest extent possible (Huang and Wang 1995). Information diffusion can be divided into two ways: one is to assign single-value samples to different discrete points to achieve data fuzziness, and the other is to find the information matrix determined by the discrete points of the two universes to get a fuzzy relationship between the two (He et al. 2008). This article adopted the second way to build a prediction model.

It is key to accurately detect the properties of wooden members for correctly evaluating the bearing capacity and service life of ancient wooden structure members. This has been proved in many on-site nondestructive testing practices. Based on the principle of information diffusion and the original data obtained by nondestructive testing technology, this paper established the distance (D) between the larch wood from the bark to the pulp pith, the height $(\mathrm{H})$ from the base to the top of the tree, and the dynamic elastic modulus forecasting model. During on-site operation, determining the actual location of the measurement point on the cross-section and longitudinal section firstly, then, checking the $E_{\mathrm{d}}$, collecting and summarizing all the results, removing the error value points, and selecting the proper weight value, then the $E_{\mathrm{d}}$ of the component is obtained. This study hopes to provide a basis and reference value for the rapid and accurate detection of the dynamic elastic modulus of ancient wooden structure members.

\section{EXPERIMENTAL}

\section{Materials}

The experimental materials were selected from larch (Larix gmelinii) materials that were above the fiber saturation point (FSP). Materials were purchased from Qingdongling Timber Factory (Tangshan City, Hebei Province, China). The diameter of the base was 50 $\mathrm{cm}$, the diameter of the top was $40 \mathrm{~cm}$, and the height was $400 \mathrm{~cm}$. According to the number of annual rings and the information provided by the factory, the wood was approximately 300 to 400 years old. The wood was cut from the base to the top every $50 \mathrm{~cm}$ and was divided into 8 sections. The sections were labeled A, B, C, D, E, F, G, H and the shaded and light sides were marked (Figs. 1a, b, c). According to the standard GB 1929 (2009) for selecting test specimens, each section was sawn into $2 \mathrm{~cm} \times 2 \mathrm{~cm} \times 45 \mathrm{~cm}$ specimens. A 
total of 559 flawless specimens were selected. The test specimens were divided into 10 groups according to the actual depth (Tables 1a, b). Among these, group 1 was the pith, and group 10 was the bark. The number of specimens in each group is shown in Table 2 . Group A was the base, and group $\mathrm{H}$ was the top.

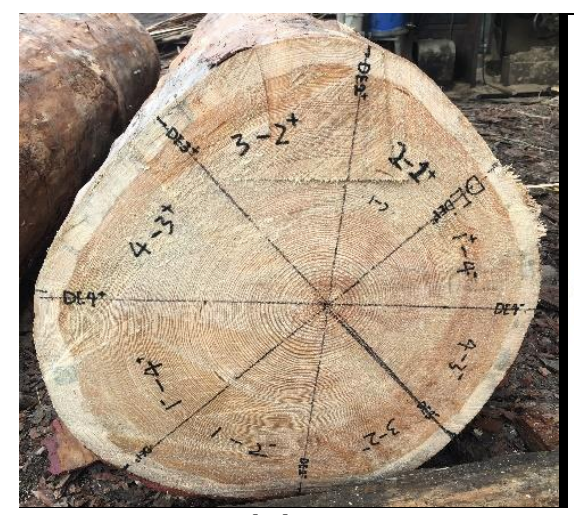

(a)

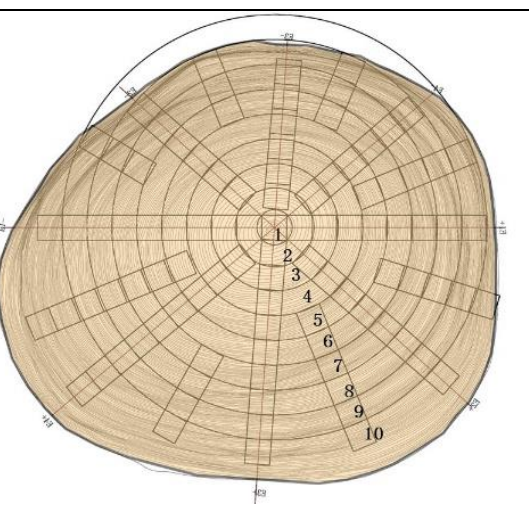

(b)

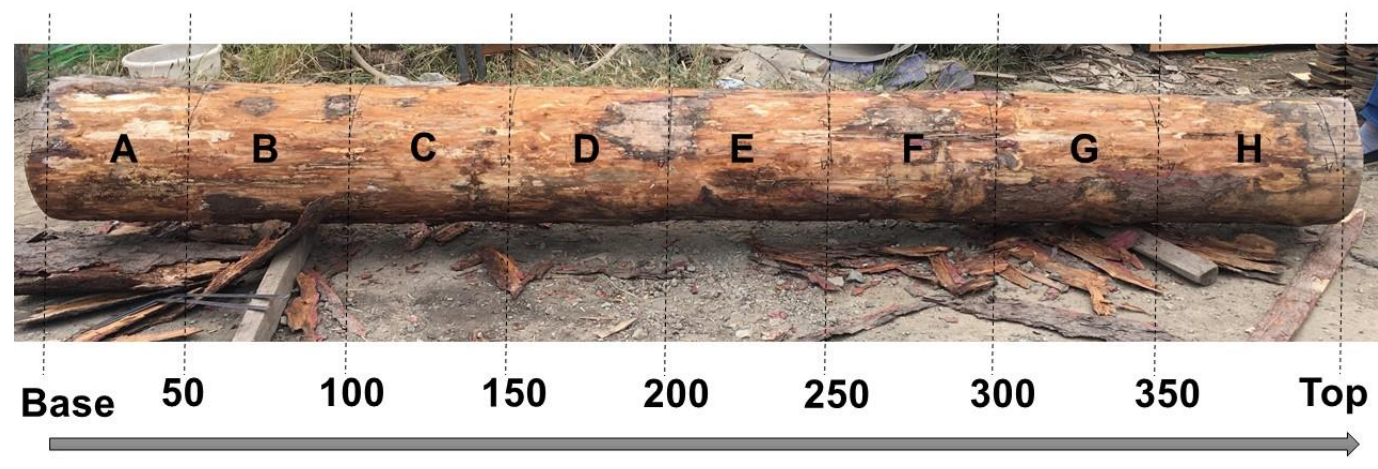

(c)

Fig. 1. Schematic diagram of cross-section and radial sections: (a) schematic diagram of crosssection, (b) schematic diagram of cross-section interception, and (c) schematic diagram of radial section

Table 1(a). Groups Listed by Depth in Cross-section

\begin{tabular}{|c|c|c|c|c|c|c|c|c|c|c|}
\hline Group Name & 1 & 2 & 3 & 4 & 5 & 6 & 7 & 8 & 9 & 10 \\
\hline Depth $(\mathrm{cm})$ & 19.1 & 16.98 & 14.88 & 12.71 & 10.68 & 8.06 & 6.51 & 4.40 & 3.78 & 2.88 \\
\hline
\end{tabular}

Table 1(b). Groups Listed by Height in Radial Section

\begin{tabular}{|c|c|c|c|c|c|c|c|c|}
\hline Group Name & A & B & C & D & E & F & G & H \\
\hline Height $(\mathrm{cm})$ & 50 & 100 & 150 & 200 & 250 & 300 & 350 & 400 \\
\hline
\end{tabular}


Table 2. Number of Specimens in Each Group

\begin{tabular}{|c|c|c|c|c|c|c|c|c|c|c|}
\hline \multirow{2}{*}{ Section Name } & \multicolumn{10}{|c|}{ Group Name } \\
\cline { 2 - 12 } & 1 & 2 & 3 & 4 & 5 & 6 & 7 & 8 & 9 & 10 \\
\hline A & 1 & 4 & 6 & 6 & 8 & 10 & 15 & 14 & 7 & 4 \\
\hline B & 1 & 2 & 5 & 7 & 8 & 10 & 13 & 13 & 7 & 4 \\
\hline C & 1 & 3 & 6 & 7 & 8 & 11 & 13 & 12 & 7 & 4 \\
\hline D & 1 & 3 & 6 & 7 & 7 & 8 & 11 & 10 & 6 & 4 \\
\hline E & 1 & 2 & 7 & 8 & 9 & 9 & 13 & 12 & 5 & 4 \\
\hline F & 1 & 2 & 6 & 8 & 9 & 10 & 12 & 12 & 5 & 4 \\
\hline G & 1 & 3 & 6 & 8 & 8 & 9 & 12 & 11 & 5 & 4 \\
\hline H & 1 & 4 & 8 & 8 & 9 & 9 & 13 & 12 & 5 & 4 \\
\hline
\end{tabular}

\section{Equipment}

The apparatuses used were a Lichen Technology blast dryer box 101-3BS (Shanghai Lichen Electronic Technology Co., Ltd., Shanghai, China), Lichen Technology electronic precision balance JA1003 (Shanghai Lichen Electronic Technology Co., Ltd., Shanghai, China), Vernier calipers (Guilin Guanglu Measuring Instrument Co., Ltd., Guilin, China), and FAKOPP microsecond timber (FAKOPP Enterprise Bt., Ágfalva, Hungary)( Figs. 2a, b, c, d).

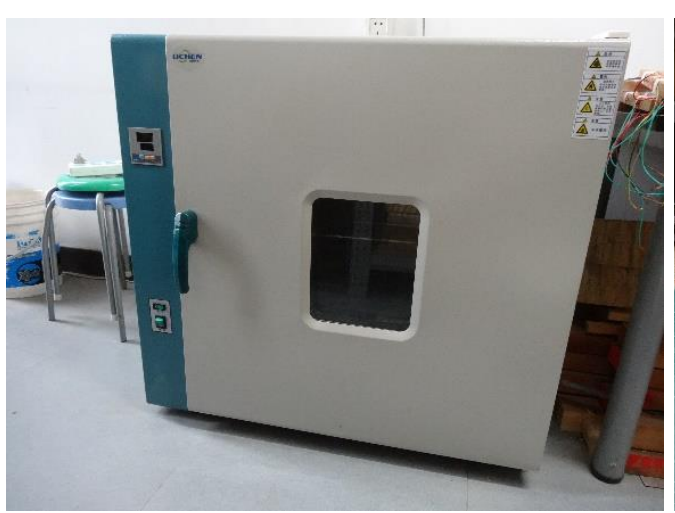

(a)

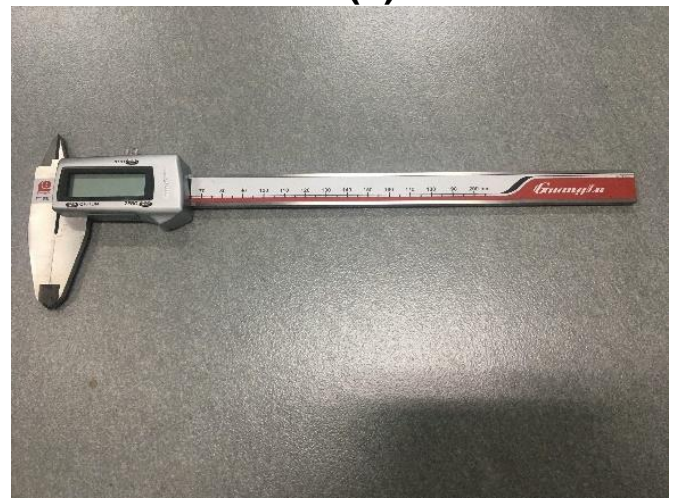

(c)

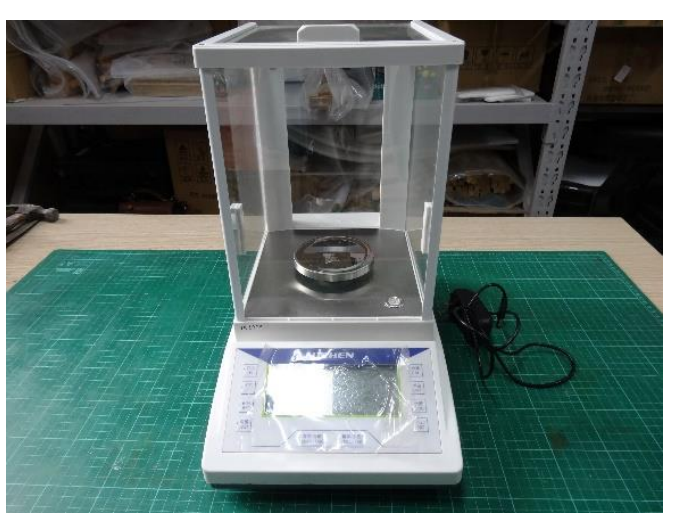

(b)

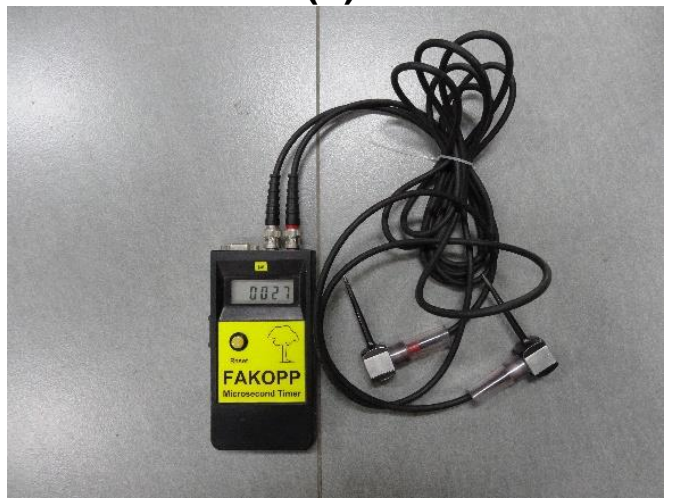

(d)

Fig. 2. Experiment equipment-- (a) dryer box; (b) electronic precision balance; (c) Vernier calipers; and (d) FAKOPP microsecond timber 


\section{Methodology Adopted}

The propagation time of stress wave in wood was measured with a stress wave tester FAKOPP (FAKOPP Enterprise Bt., Ágfalva, Hungary). The two probes of the instrument were inserted into both ends of the test specimens and the propagation time was measured along the longitudinal direction of the test specimens. The angle between the two probes and the length of the test specimens was not less than $45^{\circ}$, and the distance between the two measurement points was measured, as shown in Fig. 3. During the measurement, the reading of the propagation time of the first tap was invalid. Starting from the second time, the average value of the propagation time obtained by continuously measuring three times was used as the final test result. According to the application principle of the stress wave tester (Zhang and Wang 2014), the propagation velocity and dynamic modulus of elasticity of the wood $\left(E_{\mathrm{d}}\right)$ were calculated using Eqs. 1 and 2. According to the actual position of specimens and the division method of the group, the average in the group was taken as the value of the stress wave propagation velocity and the $E_{\mathrm{d}}$, see Table 3 ,

$$
C_{\mathrm{c}}=10^{6} \times(L / T)
$$

where $L$ is the distance between the two sensors of the stress wave tester (m), $T$ is the time recorded between the two sensors of the stress wave tester $(\mu \mathrm{s})$, and $C_{\mathrm{c}}$ is the stress wave propagation velocity in wood $(\mathrm{m} / \mathrm{s})$. Equation 2 is as follows,

$$
E_{\mathrm{d}}=\rho C_{\mathrm{c}}^{2}
$$

where $E_{\mathrm{d}}$ is the dynamic modulus of elasticity of wood (MPa), $\rho$ was the density of wood $\left(\mathrm{g} / \mathrm{cm}^{3}\right)$.

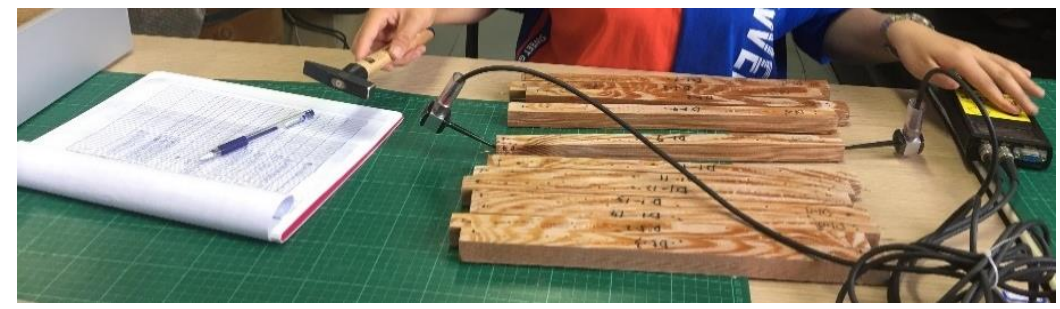

Fig. 3. Measuring the stress wave propagation time

Table 3. Dynamic Elastic Modulus of Wood at Each Location Measured by Nondestructive Testing

\begin{tabular}{|c|c|c|c|c|c|c|c|}
\hline $\begin{array}{c}\text { Serial } \\
\text { Number }\end{array}$ & $\mathrm{D}(\mathrm{cm})$ & $\begin{array}{c}\mathrm{H} \\
(\mathrm{cm})\end{array}$ & $\begin{array}{c}E_{\mathrm{d}} \\
(\mathrm{GPa})\end{array}$ & $\begin{array}{c}\text { Serial } \\
\text { Number }\end{array}$ & $\begin{array}{c}\mathrm{D} \\
(\mathrm{cm})\end{array}$ & $\begin{array}{c}\mathrm{H} \\
(\mathrm{cm})\end{array}$ & $\begin{array}{c}E_{\mathrm{d}} \\
(\mathrm{GPa})\end{array}$ \\
\hline 1 & 19.10 & 50 & 8.60 & 41 & 8.06 & 50 & 11.92 \\
\hline 2 & 19.10 & 100 & 9.30 & 42 & 8.06 & 100 & 13.10 \\
\hline 3 & 19.10 & 150 & 7.24 & 43 & 8.06 & 150 & 13.51 \\
\hline 4 & 19.10 & 200 & 6.48 & 44 & 8.06 & 200 & 12.24 \\
\hline 5 & 19.10 & 250 & 5.72 & 45 & 8.06 & 250 & 9.83 \\
\hline 6 & 19.10 & 300 & 7.05 & 46 & 8.06 & 300 & 12.12 \\
\hline 7 & 19.10 & 350 & 6.82 & 47 & 8.06 & 350 & 11.93 \\
\hline 8 & 19.10 & 400 & 6.28 & 48 & 8.06 & 400 & 12.02 \\
\hline
\end{tabular}




\begin{tabular}{|c|c|c|c|c|c|c|c|}
\hline 9 & 16.98 & 50 & 9.67 & 49 & 6.51 & 50 & 11.76 \\
\hline 10 & 16.98 & 100 & 8.97 & 50 & 6.51 & 100 & 12.85 \\
\hline 11 & 16.98 & 150 & 9.67 & 51 & 6.51 & 150 & 12.71 \\
\hline 12 & 16.98 & 200 & 10.17 & 52 & 6.51 & 200 & 12.73 \\
\hline 13 & 16.98 & 250 & 6.75 & 53 & 6.51 & 250 & 10.47 \\
\hline 14 & 16.98 & 300 & 8.07 & 54 & 6.51 & 300 & 12.34 \\
\hline 15 & 16.98 & 350 & 7.51 & 55 & 6.51 & 350 & 12.90 \\
\hline 16 & 16.98 & 400 & 8.24 & 56 & 6.51 & 400 & 12.69 \\
\hline 17 & 14.88 & 50 & 11.45 & 57 & 4.40 & 50 & 11.78 \\
\hline 18 & 14.88 & 100 & 12.43 & 58 & 4.40 & 100 & 13.11 \\
\hline 19 & 14.88 & 150 & 12.33 & 59 & 4.40 & 150 & 13.21 \\
\hline 20 & 14.88 & 200 & 10.88 & 60 & 4.40 & 200 & 12.93 \\
\hline 21 & 14.88 & 250 & 8.75 & 61 & 4.40 & 250 & 10.16 \\
\hline 22 & 14.88 & 300 & 10.10 & 62 & 4.40 & 300 & 12.22 \\
\hline 23 & 14.88 & 350 & 10.57 & 63 & 4.40 & 350 & 13.42 \\
\hline 24 & 14.88 & 400 & 10.31 & 64 & 4.40 & 400 & 12.75 \\
\hline 25 & 12.71 & 50 & 12.35 & 65 & 3.78 & 50 & 12.43 \\
\hline 26 & 12.71 & 100 & 13.48 & 66 & 3.78 & 100 & 13.87 \\
\hline 27 & 12.71 & 150 & 13.58 & 67 & 3.78 & 150 & 13.31 \\
\hline 28 & 12.71 & 200 & 12.43 & 68 & 3.78 & 200 & 13.19 \\
\hline 29 & 12.71 & 250 & 10.89 & 69 & 3.78 & 250 & 10.38 \\
\hline 30 & 12.71 & 300 & 12.44 & 70 & 3.78 & 300 & 13.10 \\
\hline 31 & 12.71 & 350 & 11.81 & 71 & 3.78 & 350 & 13.92 \\
\hline 32 & 12.71 & 400 & 12.45 & 72 & 3.78 & 400 & 13.43 \\
\hline 33 & 10.68 & 50 & 11.75 & 73 & 2.88 & 50 & 13.14 \\
\hline 34 & 10.68 & 100 & 12.97 & 74 & 2.88 & 100 & 13.99 \\
\hline 35 & 10.68 & 150 & 12.66 & 75 & 2.88 & 150 & 14.11 \\
\hline 36 & 10.68 & 200 & 12.38 & 76 & 2.88 & 200 & 13.48 \\
\hline 37 & 10.68 & 250 & 9.88 & 77 & 2.88 & 250 & 10.15 \\
\hline 38 & 10.68 & 300 & 11.81 & 78 & 2.88 & 300 & 12.53 \\
\hline 39 & 10.68 & 350 & 11.89 & 79 & 2.88 & 350 & 12.49 \\
\hline 40 & 10.68 & 400 & 12.09 & 80 & 2.88 & 400 & 12.04 \\
\hline
\end{tabular}

Next, to determine the density and the moisture content (MC). According to Fig. 4 to cut off the specimens, the size was $2 \mathrm{~cm} \times 2 \mathrm{~cm} \times 2 \mathrm{~cm}$. It was measured with a Vernier caliper (Guilin Guanglu Measuring Instrument Co., Ltd., Guilin, China), and the mass of the test specimens was recorded with a balance. The density calculation formula, $\rho=M$ / $V$, was then used to calculate the density of all the test specimens. Where, $M$ was the mass (g), $V$ was the volume $\left(\mathrm{cm}^{3}\right)$. According to the actual position of specimens and the division method of the group, the average in the group was taken as the value of the density. 


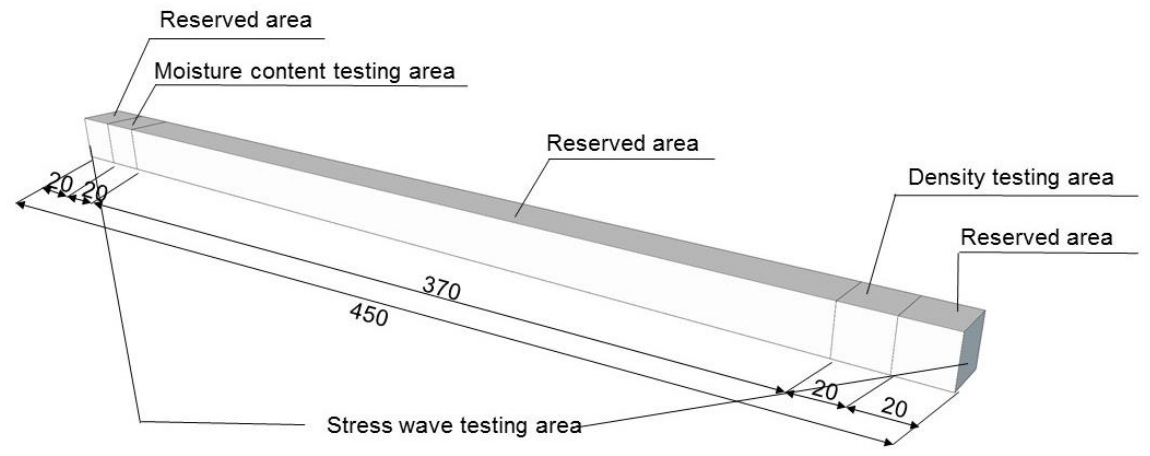

Fig. 4. Experimental specimen partition (units are in $\mathrm{mm}$ )

The MC of the test specimens was then determined according to the GB 1931 (1991) standard (Fig. 5). After drying in a drying box, the mass of the wooden block was measured, and the MC was calculated. The measurement results showed that the MC was $4 \% \sim 7 \%$.

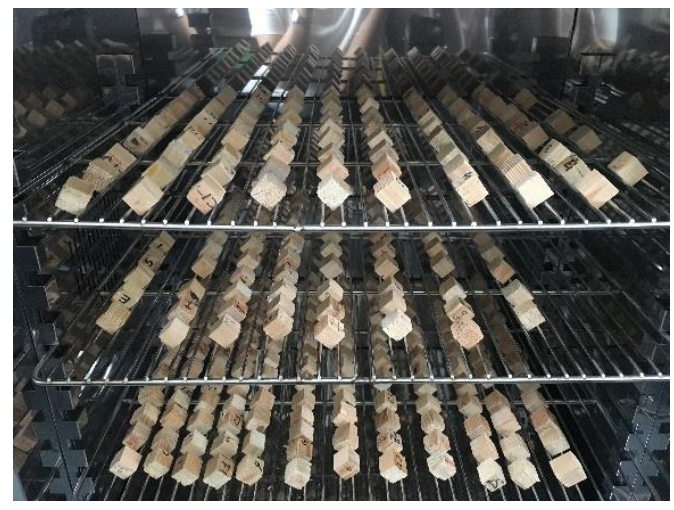

Fig. 5. Determination of moisture content by drying test specimens

\section{RESULTS AND DISCUSSION}

\section{Establishment of Matrix Model}

Establishment of fuzzy matrix between $E_{d}$ and cross-sectional depth and radial section height

First, a fuzzy relationship between the cross-section distance (D) from the bark to the pith and the $E_{\mathrm{d}}$ was established. The range of D was 1 to 19 , and the range of $E_{\mathrm{d}}$ was 5 to 15. The domain of discourse of the two was taken as Eq. 3,

$$
U_{D}=\{1,3,5,7,9,11,13,15,17,19\} ; V_{E}=\{5,7,9,11,13,15\}
$$

where $U_{\mathrm{D}}$ is the domain of the cross-section distance, with a step size $\Delta=2$; and $V_{\mathrm{E}}$ is the domain of the $E_{\mathrm{d}}$ with a step size $\Delta=2$.

This study selected the two-dimensional normal diffusion drop formula,

$$
Q=f_{m}(u, v)=\frac{1}{2 \pi m h^{2}} \sum_{j=1}^{m} \exp \left[-\frac{\left(u^{\prime}-u_{j}^{\prime}\right)^{2}+\left(v^{\prime}-v_{j}^{\prime}\right)^{2}}{2 h^{2}}\right]
$$


where $u^{\prime}=\left(u-a_{1}\right) /\left(b_{1}-a_{1}\right) ; v^{\prime}=\left(v-a_{2}\right) /\left(b_{2}-a_{2}\right) ; u_{\mathrm{j}}^{\prime}=\left(u_{\mathrm{j}}-a_{1}\right) /\left(b_{1}-a_{1}\right) ; v_{\mathrm{j}}^{\prime}=\left(v_{\mathrm{j}}-a_{2}\right) /$ $\left(b_{2}-a_{2}\right) ; a_{1}=\min \left(u_{\mathrm{j}}\right), 1 \leq j \leq m ; b_{1}=\max \left(u_{\mathrm{j}}\right), 1 \leq j \leq m ; a_{2}=\min \left(v_{\mathrm{j}}\right), 1 \leq j \leq m ; b_{2}=\max \left(v_{\mathrm{j}}\right)$, $1 \leq j \leq m ; u_{\mathrm{j}}$ is the discrete point of $\mathrm{U}$, and $v_{\mathrm{j}}$ is the discrete point of $\mathrm{U}$, where $j=[1,2, \ldots$, $r]$. The variable $h$ can be found using the equation $h=1.4208 /(\mathrm{m}-1)$, where $\mathrm{m}$ is the number of samples.

Using Eq. 3, the original information distribution matrix $Q_{\mathrm{D}, \mathrm{E}}$ was obtained, and the original information was completed by normalization processing to obtain the fuzzy relation matrix $R_{\mathrm{D}, \mathrm{E}}$ between the cross-section distance (D) from the bark to the pith and the $E_{\mathrm{d}}$. Using the MATLAB software (MathWorks, Inc., Natick, MA, USA) to calculate, the results are shown in Table 4.

Table 4. Initial Information Distribution Matrix $Q_{D, E}$

\begin{tabular}{|c|c|c|c|c|c|c|}
\hline & $D_{1}(5)$ & $D_{2}(7)$ & $D_{3}(9)$ & $D_{4}(11)$ & $D_{5}(13)$ & $D_{6}(15)$ \\
\hline$M_{1}(1)$ & 0.000 & 0.000 & 0.000 & 0.000 & 0.000 & 0.000 \\
\hline$M_{2}(3)$ & 0.000 & 0.000 & 0.000 & 0.000 & 4.014 & 0.000 \\
\hline$M_{3}(5)$ & 0.000 & 0.000 & 0.000 & 0.000 & 1.721 & 0.000 \\
\hline$M_{4}(7)$ & 0.000 & 0.000 & 0.000 & 0.003 & 2.848 & 0.000 \\
\hline$M_{5}(9)$ & 0.000 & 0.000 & 0.000 & 0.000 & 0.028 & 0.000 \\
\hline$M_{6}(11)$ & 0.000 & 0.000 & 0.000 & 0.000 & 3.571 & 0.000 \\
\hline$M_{7}(13)$ & 0.000 & 0.000 & 0.000 & 2.877 & 0.038 & 0.000 \\
\hline$M_{8}(15)$ & 0.000 & 0.000 & 1.433 & 4.283 & 0.005 & 0.000 \\
\hline$M_{9}(17)$ & 0.000 & 1.576 & 6.017 & 0.000 & 0.000 & 0.000 \\
\hline$M_{10}(19)$ & 0.000 & 9.989 & 0.976 & 0.000 & 0.000 & 0.000 \\
\hline
\end{tabular}

$$
R_{\mathrm{D}, E}=\left|\begin{array}{cccccc}
0 & 0 & 0 & 0 & 1 & 0 \\
0 & 0 & 0 & 0 & 1 & 0 \\
0 & 0 & 0 & 0 & 1 & 0 \\
0 & 0 & 0 & 0.001 & 1 & 0 \\
0 & 0 & 0 & 0 & 1 & 0 \\
0 & 0 & 0 & 0 & 1 & 0 \\
0 & 0 & 0 & 1 & 0.013 & 0 \\
0 & 0 & 0.334 & 1 & 0.01 & 0 \\
0 & 0.262 & 1 & 0 & 0 & 0 \\
0 & 0 & 0.098 & 0 & 0 & 0
\end{array}\right|
$$

Similarly, the fuzzy relation between the height $(\mathrm{H})$ from the base to the top in the radial section and $E_{\mathrm{d}}$ could be obtained, and then the original information distribution matrix $Q_{\mathrm{H}, \mathrm{E}}$ and the fuzzy relation matrix $R_{\mathrm{H}, \mathrm{E}}$ could be gained, as shown in Table 5 . 
Table 5. Initial Information Distribution Matrix $Q_{\mathrm{H}, \mathrm{E}}$

\begin{tabular}{|c|c|c|c|c|c|c|}
\hline & $D_{1}(5)$ & $D_{2}(7)$ & $D_{3}(9)$ & $D_{4}(11)$ & $D_{5}(13)$ & $D_{6}(15)$ \\
\hline $\mathrm{H}_{1}(1)$ & 0.000 & 0.000 & 0.184 & 0.072 & 4.005 & 0.000 \\
\hline $\mathrm{H}_{2}(3)$ & 0.000 & 0.000 & 6.883 & 0.000 & 19.480 & 0.000 \\
\hline $\mathrm{H}_{3}(5)$ & 0.000 & 1.736 & 0.000 & 0.000 & 4.561 & 0.000 \\
\hline $\mathrm{H}_{4}(7)$ & 0.000 & 0.016 & 0.000 & 4.483 & 9.593 & 0.000 \\
\hline $\mathrm{H}_{5}(9)$ & 0.000 & 1.559 & 1.559 & 4.730 & 0.000 & 0.000 \\
\hline $\mathrm{H}_{6}(11)$ & 0.000 & 5.822 & 0.000 & 0.000 & 4.993 & 0.000 \\
\hline $\mathrm{H}_{7}(13)$ & 0.000 & 3.040 & 0.000 & 0.106 & 5.086 & 0.000 \\
\hline $\mathrm{H}_{8}(15)$ & 0.000 & 0.000 & 0.000 & 0.000 & 2.418 & 0.000 \\
\hline
\end{tabular}

$$
R_{H, E}=\left|\begin{array}{cccccc}
0 & 0 & 0.046 & 0.018 & 1 & 0 \\
0 & 0 & 0.353 & 0 & 1 & 0 \\
0 & 0.386 & 0 & 0 & 1 & 0 \\
0 & 0.002 & 0 & 0.467 & 1 & 0 \\
0 & 0.330 & 0.330 & 1 & 0 & 0 \\
0 & 1 & 0 & 0 & 0.858 & 0 \\
0 & 0.600 & 0 & 0.021 & 1 & 0 \\
0 & 0 & 0 & 0 & 1 & 0
\end{array}\right|
$$

Fuzzy approximate reasoning

In the construction of the model, the approximate inference formula, $B_{\mathrm{i}}=A_{\mathrm{i}} \times R$, was used for prediction, where $A_{\mathrm{i}}$ in the formula was calculated according to Eq. 5,

$$
\begin{aligned}
& \text { when } a \leq a_{\min }, a_{\min } \in A_{\mathrm{i}}, A_{\mathrm{i}}=[1,0, \cdots, 0] \\
& \text { when } a \geq a_{\max }, a_{\max } \in A_{\mathrm{i}}, A_{\mathrm{i}}=[0,0, \cdots, 1] \\
& \text { when } a_{\min } \leq a \leq a_{\max }, A_{\mathrm{i}}=\left[\max \left(0,1-\left|a-a_{\mathrm{i}}\right| / \Delta\right)\right]
\end{aligned}
$$

where $\Delta$ is the step size; $\Delta=a_{\mathrm{i}+1}-a_{\mathrm{i}} ;(i=1,2, \cdots, \mathrm{m})$.

The above is the first-order fuzzy approximation inference process. The cross and radial sections have different degrees of influence on the $E_{\mathrm{d}}$ (Fig. 6). Therefore, the secondorder fuzzy approximation inference should be completed based on the influence.

According to Eq. 6, the result of the second-order fuzzy approximation inference can be obtained by the combination operation of Weight Array $A^{\prime}$ and Fuzzy Matrix $R^{\prime}$,

$$
B^{\prime}=A^{\prime} \times R^{\prime}
$$

where $A^{\prime}$ is the influence weight of each variable.

In this study, the $A^{\prime}$ value was determined by a cross-combination operation of two measured variables under different influence weights. Upon calculation, when the influence weight of the $\mathrm{D}$ and $\mathrm{H}$ was $A^{\prime}=[0.7,0.3]$, the average relative error of the predicted value was minimal, which was $8.55 \%$ (Figs. 6a, b; Fig. 7). In Fig. 6a, 2 was closer to the bark, and 19 was closer to the pith. In Fig. 6 b, 0 was the base, and 400 was the top. 


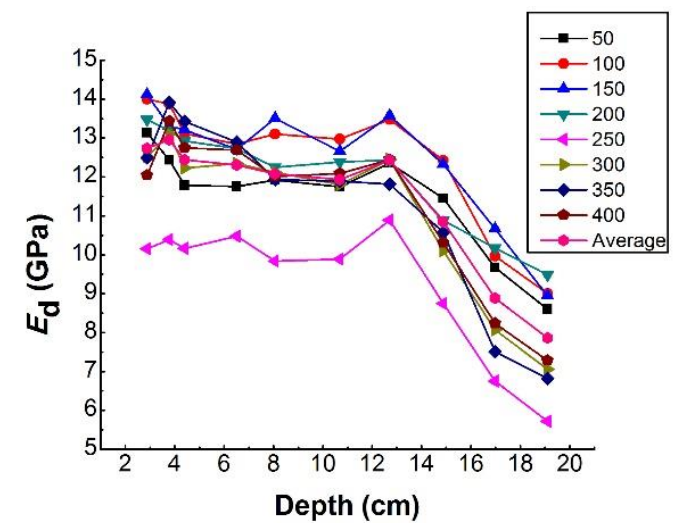

(a)

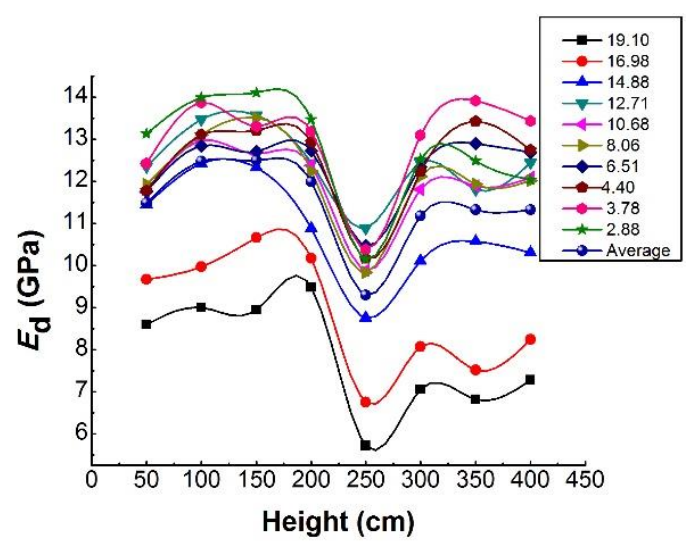

(b)

Fig. 6. Variation of $E_{d}$ in (a) cross-section and (b) radial section

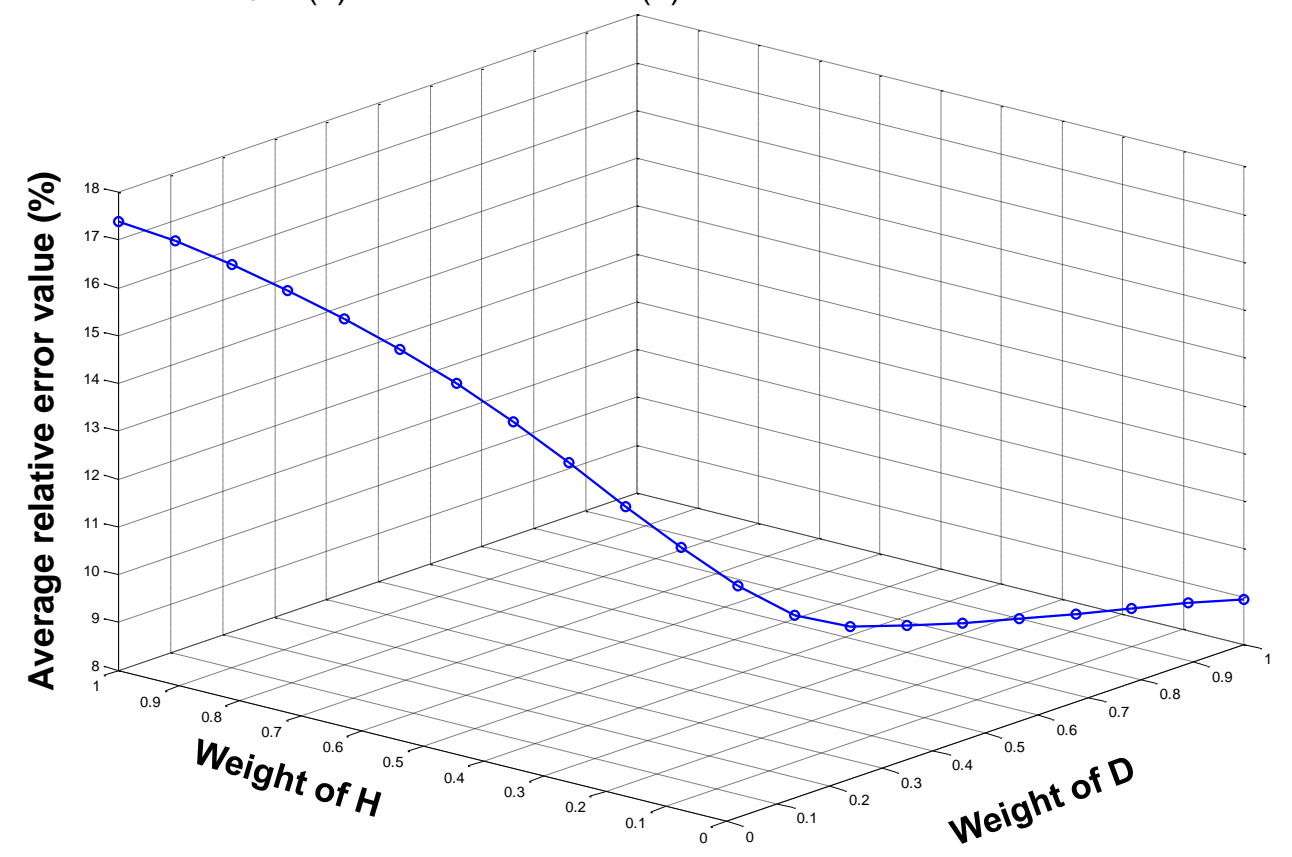

Fig. 7. Cross-combined calendar optimization algorithm calculates weights of influencing factors

\section{Data normalization}

To obtain the best predicted value, $B^{\prime}$ is replaced into Eq. 7 , and the result is the final predicted value,

$$
D=\frac{\sum_{i=1}^{n}\left(B_{i}^{\prime}\right)^{k} \cdot D_{i}}{\sum_{i=1}^{n}\left(B_{i}^{\prime}\right)^{k}}
$$

where $D$ is the final predicted value of $E_{d} ; D_{i}$ is the grade value of $E_{d} ; k$ is a constant as appropriate, and $k=2$ in this article.

Table 6 compares the results of the measured and predicted values of the $E_{\mathrm{d}}$ of larch under the information diffusion method, and the relative errors of the two results. It can be seen from the data and the prediction map that the model based on the information diffusion 
method predicts the relationship between the distance (D) from the bark to the pith, the height $(\mathrm{H})$ from the base to the top of the wood, and the $E_{\mathrm{d}}$, which is effective and practical. The information diffusion model does not need to understand the distribution of samples and does not need to construct membership functions. It uses the information diffusion principle to diffuse the original data. It requires less data and solves nonlinear and local minimum problems well (Zhang and Wang 2010; Li et al. 2014). These advantages are reflected in the above prediction model for the $E_{\mathrm{d}}$ of larch.

Table 6. Contrast of Predicted Value and Actual Value of $E_{\mathrm{d}}$

\begin{tabular}{|c|c|c|c|c|c|c|c|c|c|c|c|}
\hline $\begin{array}{c}\text { Serial } \\
\text { Numb } \\
\text { er }\end{array}$ & $\begin{array}{c}D \\
(\mathrm{~cm})\end{array}$ & $\begin{array}{c}\mathrm{H} \\
(\mathrm{cm})\end{array}$ & $\begin{array}{l}\text { Actual } \\
\text { Value } \\
\text { of } E_{\mathrm{d}} \\
\text { (GPa) }\end{array}$ & $\begin{array}{c}\text { Predicte } \\
\mathrm{d} \text { Value } \\
\text { of } E_{\mathrm{d}} \\
(\mathrm{GPa})\end{array}$ & $\begin{array}{c}\text { Relativ } \\
\text { e Error } \\
(\%)\end{array}$ & $\begin{array}{c}\text { Serial } \\
\text { Numb } \\
\text { er }\end{array}$ & $\begin{array}{c}\text { D } \\
(\mathrm{cm})\end{array}$ & $\begin{array}{c}\mathrm{H} \\
(\mathrm{cm})\end{array}$ & $\begin{array}{c}\text { Actual } \\
\text { Value } \\
\text { of } E_{\mathrm{d}} \\
(\mathrm{GPa})\end{array}$ & $\begin{array}{c}\text { Predicte } \\
\text { d Value } \\
\text { of } E_{d} \\
\text { (GPa) }\end{array}$ & $\begin{array}{c}\text { Relative } \\
\text { Error } \\
(\%)\end{array}$ \\
\hline 1 & 19.10 & 50 & 8.60 & 8.03 & 6.66 & 41 & 8.06 & 50 & 11.92 & 13.00 & 9.03 \\
\hline 2 & 19.10 & 100 & 9.30 & 8.07 & 13.25 & 42 & 8.06 & 100 & 13.10 & 12.96 & 1.13 \\
\hline 3 & 19.10 & 150 & 7.24 & 7.78 & 7.48 & 43 & 8.06 & 150 & 13.51 & 12.92 & 4.33 \\
\hline 4 & 19.10 & 200 & 6.48 & 8.13 & 25.41 & 44 & 8.06 & 200 & 12.24 & 12.96 & 5.86 \\
\hline 5 & 19.10 & 250 & 5.72 & 7.59 & 32.76 & 45 & 8.06 & 250 & 9.83 & 12.54 & 27.47 \\
\hline 6 & 19.10 & 300 & 7.05 & 7.40 & 5.03 & 46 & 8.06 & 300 & 12.12 & 12.46 & 2.86 \\
\hline 7 & 19.10 & 350 & 6.82 & 7.68 & 12.67 & 47 & 8.06 & 350 & 11.93 & 12.81 & 7.39 \\
\hline 8 & 19.10 & 400 & 6.28 & 8.02 & 27.72 & 48 & 8.06 & 400 & 12.02 & 13.00 & 8.20 \\
\hline 9 & 16.98 & 50 & 9.67 & 9.47 & 2.10 & 49 & 6.51 & 50 & 11.76 & 13.00 & 10.54 \\
\hline 10 & 16.98 & 100 & 8.97 & 9.38 & 4.65 & 50 & 6.51 & 100 & 12.85 & 12.96 & 0.85 \\
\hline 11 & 16.98 & 150 & 9.67 & 9.28 & 3.98 & 51 & 6.51 & 150 & 12.71 & 12.92 & 1.69 \\
\hline 12 & 16.98 & 200 & 10.17 & 9.54 & 6.27 & 52 & 6.51 & 200 & 12.73 & 12.96 & 1.81 \\
\hline 13 & 16.98 & 250 & 6.75 & 9.04 & 33.86 & 53 & 6.51 & 250 & 10.47 & 12.54 & 19.67 \\
\hline 14 & 16.98 & 300 & 8.07 & 8.75 & 8.37 & 54 & 6.51 & 300 & 12.34 & 12.46 & 0.97 \\
\hline 15 & 16.98 & 350 & 7.51 & 9.14 & 21.70 & 55 & 6.51 & 350 & 12.90 & 12.81 & 0.66 \\
\hline 16 & 16.98 & 400 & 8.24 & 9.49 & 15.12 & 56 & 6.51 & 400 & 12.69 & 13.00 & 2.46 \\
\hline 17 & 14.88 & 50 & 11.45 & 11.11 & 2.93 & 57 & 4.40 & 50 & 11.78 & 13.00 & 10.32 \\
\hline 18 & 14.88 & 100 & 12.43 & 10.95 & 11.85 & 58 & 4.40 & 100 & 13.11 & 12.96 & 1.19 \\
\hline 19 & 14.88 & 150 & 12.33 & 11.05 & 10.37 & 59 & 4.40 & 150 & 13.21 & 12.92 & 2.15 \\
\hline 20 & 14.88 & 200 & 10.88 & 11.10 & 2.00 & 60 & 4.40 & 200 & 12.93 & 12.96 & 0.27 \\
\hline 21 & 14.88 & 250 & 8.75 & 10.78 & 23.23 & 61 & 4.40 & 250 & 10.16 & 12.54 & 23.36 \\
\hline 22 & 14.88 & 300 & 10.10 & 10.54 & 4.28 & 62 & 4.40 & 300 & 12.22 & 12.46 & 1.95 \\
\hline 23 & 14.88 & 350 & 10.57 & 10.93 & 3.43 & 63 & 4.40 & 350 & 13.42 & 12.81 & 4.55 \\
\hline 24 & 14.88 & 400 & 10.31 & 11.13 & 8.04 & 64 & 4.40 & 400 & 12.75 & 13.00 & 1.98 \\
\hline 25 & 12.71 & 50 & 12.35 & 11.63 & 5.85 & 65 & 3.78 & 50 & 12.43 & 13.00 & 4.58 \\
\hline 26 & 12.71 & 100 & 13.48 & 11.58 & 14.06 & 66 & 3.78 & 100 & 13.87 & 12.96 & 6.63 \\
\hline 27 & 12.71 & 150 & 13.58 & 11.53 & 15.11 & 67 & 3.78 & 150 & 13.31 & 12.92 & 2.93 \\
\hline 28 & 12.71 & 200 & 12.43 & 11.47 & 7.74 & 68 & 3.78 & 200 & 13.19 & 12.96 & 1.76 \\
\hline 29 & 12.71 & 250 & 10.89 & 10.96 & 0.62 & 69 & 3.78 & 250 & 10.38 & 12.54 & 20.73 \\
\hline 30 & 12.71 & 300 & 12.44 & 10.84 & 12.86 & 70 & 3.78 & 300 & 13.10 & 12.46 & 4.87 \\
\hline 31 & 12.71 & 350 & 11.81 & 11.37 & 3.77 & 71 & 3.78 & 350 & 13.92 & 12.81 & 7.93 \\
\hline 32 & 12.71 & 400 & 12.45 & 11.64 & 6.51 & 72 & 3.78 & 400 & 13.43 & 13.00 & 3.23 \\
\hline
\end{tabular}




\begin{tabular}{|l|c|c|c|c|c|c|c|c|c|c|c|}
\hline 33 & 10.68 & 50 & 11.75 & 13.00 & 10.65 & 73 & 2.88 & 50 & 13.14 & 13.00 & 1.04 \\
\hline 34 & 10.68 & 100 & 12.97 & 12.96 & 0.12 & 74 & 2.88 & 100 & 13.99 & 12.96 & 7.41 \\
\hline 35 & 10.68 & 150 & 12.66 & 12.92 & 2.10 & 75 & 2.88 & 150 & 14.11 & 12.92 & 8.42 \\
\hline 36 & 10.68 & 200 & 12.38 & 12.96 & 4.67 & 76 & 2.88 & 200 & 13.48 & 12.96 & 3.81 \\
\hline 37 & 10.68 & 250 & 9.88 & 12.54 & 26.85 & 77 & 2.88 & 250 & 10.15 & 12.54 & 23.53 \\
\hline 38 & 10.68 & 300 & 11.81 & 12.46 & 5.55 & 78 & 2.88 & 300 & 12.53 & 12.46 & 0.50 \\
\hline 39 & 10.68 & 350 & 11.89 & 12.81 & 7.77 & 79 & 2.88 & 350 & 12.49 & 12.81 & 2.57 \\
\hline 40 & 10.68 & 400 & 12.09 & 13.00 & 7.53 & 80 & 2.88 & 400 & 12.04 & 13.00 & 7.99 \\
\hline
\end{tabular}

It can be seen from Fig. 8 a that the value of the $E_{\mathrm{d}}$ is very different from the distance (D) from the bark to the pith in the cross-section and the height $(\mathrm{H})$ from the base to the top in the radial section of the wood. The variation trend is obvious, and it demonstrates the accuracy of the prediction model. As shown in the comparison with the multiple linear regression model (Fig. 8b), the prediction results based on the information diffusion model show high accuracy and stability and can clearly reflect the difference in elastic modulus at each position. The model can also provide guarantee for improving detection accuracy. From the above calculations, it can be seen that under the influence of the two weights of the distance (D) from the bark to the pith and the height $(\mathrm{H})$ from the base to the top of the wood, the minimum average relative error of the fitting of the sample data was $8.55 \%$. The coefficient of determination between the measured value and the predicted value of the $E_{\mathrm{d}}$ was $\mathrm{R}^{2}=0.861$ (Fig. 9). Cavalheiro et al. (2018) reported that through static bending and longitudinal vibration methods to generate regression models to estimate the $E_{\mathrm{d}}$, the $\mathrm{R}^{2}$ value was 0.6265 . From the comparison, the predicted value and the actual value were in good agreement.

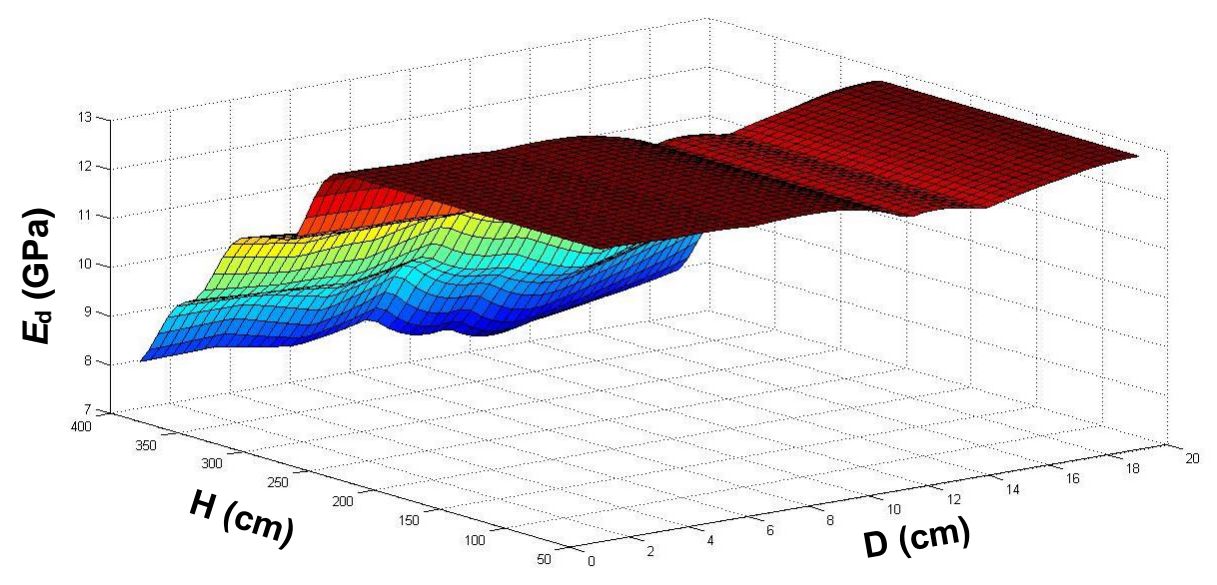

(a) Information diffusion fitting 


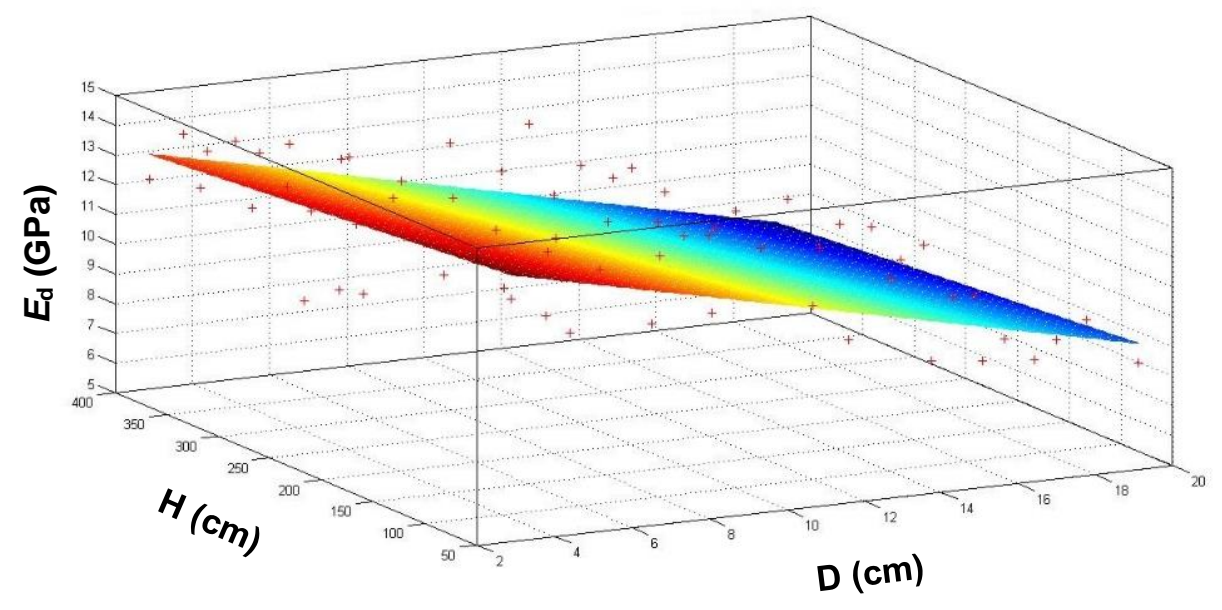

(b) Multivariate linear fitting

Fig. 8. Data fitting

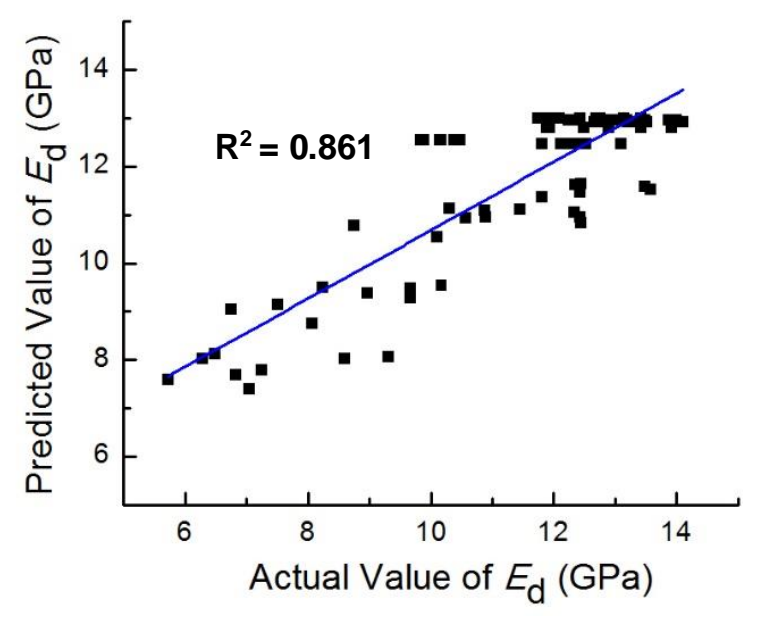

Fig. 9. Correlation between measured and predicted values

There are many factors that affect the $E_{\mathrm{d}}$ of wood in actual engineering practice, such as moisture content, temperature, density, the annual ring width, wood grain, texture, differences between heart and sapwood, and some growth defects (Liu et al. 2014). Due to the relationship between these influencing factors and $E_{\mathrm{d}}$, the detection results will be greatly different (Fig. 6b). Therefore, these constraints often cannot obtain enough sample data to estimate, so it will affect the accuracy of the prediction model. From the overall analysis, it can be seen that the prediction model proposed in this paper is still effective, it can provide a basis for evaluating the $E_{\mathrm{d}}$ of wood and provide a basis for further in-depth research, and it can also provide reference value for other related study on wood properties. 


\section{CONCLUSIONS}

1. Based on the information diffusion method, a prediction model was established between the distance (D) from the bark to the pith, the height $(\mathrm{H})$ from the base to the top, and the $E_{\mathrm{d}}$. Through analysis, the model is effective and practical. The coefficient of determination between the measured value and the predicted value of the $E_{\mathrm{d}}$ was 0.861 , they were in good agreement. In actual field testing, when a sufficient number of distances (D) and heights (H) cannot be obtained, the accuracy of detecting the dynamic elastic modulus $\left(E_{\mathrm{d}}\right)$ of wood can be improved by using the information diffusion method. It provides a basis for field work.

2. The calculation results showed that when the weights of the two influencing factors (D and $\mathrm{H}$ ) were 0.7 and 0.3 , the average relative error of the fitted sample data was the minimum, which was $8.55 \%$.

3. Compared with the multiple linear regression method, the prediction model based on the information diffusion method avoids the calculation of membership functions, and the prediction accuracy and stability of the model are significantly improved.

\section{ACKNOWLEDGMENTS}

This study was supported by the National Natural Science Foundation of China (51678005), Beijing Natural Science Foundation (8182008), the National Key R\&D Program of China (Grant No. 2018YFD1100902-1), Beijing Municipal Commission of Education-Municipal Natural Science Joint Foundation (Grant No. KZ202010005012), and Beijing Municipal Commission of Education-Municipal Natural Science Joint Foundation (KZ202010005012).

\section{REFERENCES CITED}

Biechele, T., Chui, Y. H., and Gon, M. (2011). "Comparison of NDE techniques for assessing mechanical properties of unjointed and finger-jointed lumber," Holzforschung 65(3), 397-401. DOI: 10.1515/HF.2011.038

Cavalheiro, R. S., De Almeida, D. H., De Almeida, T. H., Christoforo, A. L., and Lahr, F. A. R. (2018). "Estimation of modulus of elasticity in static bending of wood in structural dimensions as a function of longitudinal vibration and density," Current Journal of Applied Science and Technology 26(1), 1-8. DOI: 10.9734/CJAST/2018/39531

Chang, L. H. (2017). Research on Wooden Components Damages and Material Property Appropriate Technology Test of Buildings Based on Preventive Protection, Ph.D. Dissertation, Beijing University of Technology, Beijing, China.

Dackermann, U., Elsener, R., Li, J., and Crews, K. (2016). "A comparative study of using static and ultrasonic material testing methods to determine the anisotropic material properties of wood," Construction and Building Materials 102(Part 2), 963-976. DOI: 10.1016/j.conbuildmat.2015.07.195

Dahlen, J., Antony, F., Schimleck, L. R., and Daniels, R. F. (2018). "Relationships between static mechanical properties and SilviScan measured wood properties in 
loblolly pine," Forest Products Journal 68(1), 37-42. DOI: 10.13073/FPJ-D-1500044

GB 1929 (2009). "Method of sample logs sawing and test specimens selection for physical and mechanical tests of wood," Standardization Administration of China, Beijing, China.

GB 1931 (1991). "Method for determination of the moisture content of wood," Standardization Administration of China, Beijing, China.

Guan, X., Zhao, M., and Wang, Z. (2013). "Research progress in wood material testing based on stress wave technology," Forestry Machinery and Woodworking Equipment 41(2), 15-17. DOI: 10.3969/j.issn.2095-2953.2013.02.005

Hao, L., Zhang, X., and Shu, Z. (2010). "Risk assessment model to natural disaster in country unit based on information diffusion technology," Advanced Materials Research 225-226, 839-842. DOI: 10.4028/www.scientific.net/AMR.225-226.839

Haseli, M., Layeghi, M., and Hosseinabadi, H. Z. (2020). "Evaluation of modulus of elasticity of date palm sandwich panels using ultrasonic wave velocity and experimental models," Measurement 149, Article 107016. DOI: 10.1016/j.measurement.2019.107016

He, S., Wang, J., Wang, H., and Han, X. (2008). "The evaluation of loess slope stability based on combination of information diffusion theory and BP neural network," Journal of Northwest University (Natural Science Edition) 1238(6), 983-988. DOI: 10.16152/j.cnki.xdxbzr.2008.06.026

Hou, H. (2019). Prediction Method of Compressive Elastic Modulus of Solid Wood Sheet Based on Fiber Angle Detection, Master's Thesis, Northeast Forestry University, Harbin, China.

Huang, C. (2005). Theory and Practice of Natural Disaster Risk Assessment, Science Press, Beijing, China.

Huang, C., and Wang, J. (1995). Fuzzy Information Optimization Processing Technology and its Application, Beijing University of Aeronautics and Astronautics Press, Beijing, China.

Li, B., Ma, D., Su, J., and Wang, W. (2014). "Estimation method for surface rupture width under strong earthquake based on information diffusion," Journal of Basic Science and Engineering 22(2), 294-304. DOI: 10.3969/j.issn.1005-0930.2014.02.010

Li, X. (2015). Key Technology Research on Material Performance and Damage Detection for Wooden Components of Ancient Chinese Building, Ph.D. Dissertation, Beijing University of Technology, Beijing, China.

Liu, Y., Wang, L., and Sun, M. (2014). "Study on the correlation between standing timber, log and board of Mongolian scotch pine in stress wave propagation velocity," Forestry Machinery and Woodworking Equipment 2014(11), 42-47. DOI: 10.13279/j.cnki.fmwe.2014.0011

Menezzi, C., Amorim, M., Costa, M., and Garcez, L. R. O. (2014). "Evaluation of thermally modified wood by means of stress wave and ultrasound nondestructive methods," Materials Science 20(1), 61-66. DOI: 10.5755/j01.ms.20.1.3341

Ming, C., Lin, C., and Yang, T. (2013). "Application of nondestructive methods to evaluate mechanical properties of 32-year-old Taiwan incense cedar (Calocedrus formosana) wood," BioResources 8(1), 688-700. DOI: 10.15376/biores.8.1.688-700

Moreno-Chan, J., Walker, J., and Raymond, C. (2011). "Effects of moisture content and temperature on acoustic velocity and dynamic MOE of radiata pine sapwood boards," Wood Science and Technology 45(4), 609-626. DOI: 10.1007/s00226-010-0350-6 
Sun, Y. (2012). Determining Wood Density and Mechanical Properties of Ancient Architectural Timbers with Micro-Drilling Resistance, M.S. Thesis, Beijing Forestry University, Beijing, China.

Sun, Y., Zhu, L., Wang, X., Yan, H., and Liao, C. (2012). "Research on rapid detection of larch wood modulus of elasticity based on micro-drilling resistance," Hubei Agricultural Sciences 51(11), 2348-2350. DOI: 10.14088/j.cnki.issn04398114.2012.11.014

Tian, Z., Wang, Z., Wang, J., Zhang, Z., Ge, B., Lv, Y., and Ren, H. (2017). "Classification in modulus of elasticity and mechanical properties of larch lumber in Mohe," Journal of Northwest Forestry University 32(3), 211-215. DOI: 10.3969/j.issn.1001-7461.2017.03.39

Wang, C., and Zhang, H. (2006). "The research progress in wood and standing tree based on stress wave method, " Forestry Machinery and Woodworking Equipment 34(3), 913. DOI: 10.3969/j.issn.2095-2953.2006.03.003

Wang, X., Huang, Q., and Liu, J. (2019). "Risk assessment for meteorological disasters of early rice in the southern double-season based on information diffusion theory," Chinese Journal of Agrometeorology 40(11), 712-722. DOI: 10.3969/j.issn.10006362.2019.11.005

Wang, Z., Zhou, J., Gong, M., Chui, Y. H., and Lu, X. (2016). "Evaluation of modulus of elasticity of laminated strand lumber by non-destructive evaluation technique," BioResources 11(1), 626-633. DOI: 10.15376/biores.11.1.626-633

Xu, J., Lv, J., Bao, F., Xiao, J., Evans, R., Huang, R., and Xu, M. (2012). "Measuring wood properties by SilviScan- $3^{\mathrm{TM}}$ and its application in climate change research," Progressus Inquisitiones de Mutatione Climatis 8(2), 124-130. DOI: 10.3969/j.issn.1673-1719.2012.02.008

Zhang, J., and Wang, H. (2010). "Risk assessment model for regional flood disaster based on the principle of information diffusion," Journal of Water Resources \& Water Engineering 21(5), 37-39.

Zhang, W., and Wang, L. (2014). "The research progress on non-destructive testing of mechanical properties of standing trees based on stress wave method," Forest Engineering 30(2), 48-55. DOI: 10.16270/j.cnki.slgc.2014.02.010

Zhu, L. (2012). Determining the Mechanical Properties of Ancient Architectural Timber with Stress Waves, Master's Thesis, Beijing Forestry University, Beijing, China.

Zhu, L., Zhang, H., Sun, Y., and Yan, H. (2011). "Determination of mechanical properties of ancient architectural timber based on stress wave and micro-drilling resistance," Journal of Northeast Forestry University 39(10), 81-83. DOI: 10.13759/j.cnki.dlxb.2011.10.010

Article submitted: February 10, 2020; Peer review completed: April 25, 2020; Revised version received: and accepted; April 30, 2020; Published: May 7, 2020.

DOI: $10.15376 /$ biores. 15.3.4835-4850 